\title{
CONSTRUCCIÓN Y REESTRUCTURACIÓN DE LA IDENTIDAD. LA COMUNIDAD LATINOAMERICANA EN NANCY
}

\section{IRMA RAMOS SANTANA}

Groupe de recherche en information, communication et propagandes. Université Nancy 2 (France).

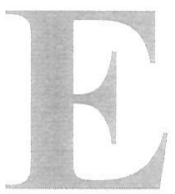

\section{RESUMEN}

n la ultima década, los flujos migratorios provenientes de América Latina se han visto incrementados notablemente en Europa, estas migraciones a corto o largo plazo forman parte integral de la dinámica mundial contemporánea que refleja las luchas geopolíticas y económicas provocadas por la globalización. Sin embargo, en la actualidad, las políticas de inmigración parecen ir en contracorriente de los recursos que los grupos de inmigrantes requieren para poder realizar su integración en la sociedad que lo recibe. Una integración que se revela además como el punto de partida de nuevas construcciones y búsquedas de identidad.

\section{INTRODUCCIÓN}

La segunda mitad del siglo XX se caracteriza por una trayectoria contradictoria: por una parte la "globalización" de la economía que favorece la libre circulación del capital, de bienes y servicios y una nueva dinámica de identidades nacionales $\mathrm{y}$, por otro lado, el cataclismo a nivel mundial de las instituciones del Estado y el retorno de las ideologías nacionalistas (Castells, 1999).

La lógica de la "globalización" querría decir que, a la libre circulación de capital y de mercancías, se podría agregar la libre circulación de personas, aunque reducida a una condición de "mano de obra", es decir, otro tipo de mercancía y, como tal, sujeta a las reglas del mercado. Mientras que en los países pobres la globalización de la riqueza benefi- 
cia a las capas sociales dominantes, en los países ricos la globalización de la pobreza alcanza amplios sectores de la población, notablemente a las personas de origen extranjero y en particular a las que se encuentran en situación irregular.

En las sociedades occidentales que resienten esta crisis económica, lo que Castells considera el cuarto mundo, el miedo del porvenir confina amplios sectores de estas sociedades en un principio de identidad fuertemente cerrado. En este contexto, los inmigrantes son considerados como una amenaza. Los discursos que designan los extranjeros como el principal factor para la inseguridad y la competencia en el mercado de trabajo se multiplican como en todo periodo de crisis encontrando un eco favorable en la opinión publica (Neveu, 1999). Como respuesta a esta situación, surgen dos ejes antagónicos: por un lado, las politicas de clausura fronteriza, y, por otro, la transformación de los flujos migratorios -de temporales se transforman en definitivos, de masculinos e individuales en familiares-.

Sin embargo, gracias a la evolución de las nuevas tecnologías de la información y de la comunicación (NTIC), la migración en la actualidad se apoya en poderosas redes sociales, tiene además un carácter oscilatorio y guarda vínculos profundos materiales y simbólicos entre los países de origen y los países huéspedes, desarrollando así formas culturales propias. De esta manera los nuevos inmigrantes pueden beneficiar de un poder de resistencia que puede en ocasiones frenar su integración en la sociedad huésped.

A continuación, analizamos la re-estructuración de las identidades de los inmigrantes, resaltando los ejes principales alrededor de los cuales estas identidades se reconstruyen.

\section{HIPÓTESIS}

Todo proceso migratorio exige una re-interpretación de la identidad, que es puesta en tela de juicio debido a la confrontación con el nuevo contexto, algunas veces muy diferente del contexto de origen. Esta confrontación impone una re-negociación de las formas de incorporación a un grupo y afecta principalmente a los inmigrantes, que deben adaptarse al nuevo estilo de vida.

La articulación entre la construcción individual de una nueva forma de identidad adaptada al nuevo estilo de vida y la conservación de un pasado anclado en una memoria colectiva adquiere estadios variables según las comunidades y las épocas. Si consideramos que las nuevas dinámicas sociales provocadas por la política neoliberal ocasionan me- 
canismos diferentes para la integración de los grupos minoritarios, no solamente a nivel local sino a nivel global, un análisis profundo de los mecanismos de construcción de la identidad en las comunidades de inmigrantes nos permitirá explicar cómo individuos que pertenecen a horizontes diferentes desarrollan dinámicas colectivas.

Durante la primera mitad del siglo XX los elementos que permitían el mantenimiento de los vínculos con la comunidad de origen eran básicamente periódicos, cartas o libros. El sentimiento de "pertenencia a una comunidad" debía apoyarse en instituciones como las escuelas, la iglesia, los partidos políticos, las asociaciones, que, entre otras tareas, garantizaban la identidad de la comunidad. En la actualidad, para las comunidades frágiles, como es el caso de los inmigrantes, la conciliación de los dos procesos de identidad no es un problema fácil de resolver, ya que la ausencia frecuente de las instituciones en esta dinámica obliga a la utilización de estrategias complejas de integración, que en un caso extremo pueden desencadenar en la formación de grupos clandestinos.

Hemos articulado este trabajo siguiendo tres ejes principales :

- Determinar las estrategias de integración que utilizan los inmigrantes en sociedades que les son frecuentemente hostiles.

- En la era de la globalización, los recursos que los grupos minoritarios pueden tener a su disposición son amplios y variados. La pregunta es cuáles y cómo son utilizados.

- Cómo la elección de una estrategia de construcción de identidad puede provocar reacciones de exclusión en la sociedad huésped.

De esta manera, queremos demostrar que en la era de la globalización las nuevas migraciones pueden significar nuevos espacios públicos donde la población inmigrante pueda encontrar los recursos necesarios para su integración $\mathrm{y}$, al mismo tiempo, ocasionar graves problemas sociales que pueden manifestarse cuando los grupos minoritarios son estigmatizados.

\section{METODOLOGÍA}

Nuestro estudio se desarrolla en la ciudad de Nancy, perteneciente al Departamento de Meurthe et Moselle, situado en la región de Lorraine, al noreste de Francia, considerada una región particularmente hospitalaria, ya que sirvió de tierra de asilo para los inmigrantes poloneses e italianos durante las primeras décadas del siglo XX (Noiriel, 2002). 
Con la articulación de diversos tipos de datos -datos demográficos sobre los inmigrantes de origen latinoamericano, los cuales abarcan desde la segunda mitad del siglo XX hasta el año 2001-y los testimonios de los actores sociales, proyectamos identificar algunas estrategias que los grupos minoritarios pueden utilizar para re-construir una identidad que se reconozca como tal en el espacio público. Para alcanzar los objetivos expuestos, la metodología utilizada se separa en dos etapas, una primera fase cuantitativa y una segunda parte cualitativa, en la que haremos uso de los testimonios recolectados.

En este trabajo otorgamos un lugar importante a las entrevistas y al trabajo de campo realizado en la ciudad de Nancy y las aglomeraciones vecinas durante un periodo comprendido entre el año 2000 y el 2004.

Nuestra muestra está constituida por una población de inmigrantes latinoamericanos que residen temporalmente en Francia por motivos de trabajo, estudios o que residen definitivamente desde hace algunos años y que, en su mayoría, pertenecen al primer periodo de inmigración de los años 70. En esta muestra, los individuos son de diversas nacionalidades: argentina, brasileña, chilena, colombiana, cubana, ecuatoriana, guatemalteca, peruana, mexicana, uruguaya y venezolana. Su residencia en Nancy varía desde un año a más de 30 años. La edad de los individuos de la muestra oscila entre 16 y 65 años. En el periodo en el que este estudio se realizó, ciertos individuos regresaron a su país de origen, sin embargo, globalmente, existe una renovación constante de la población. En lo que respecta a los individuos que residen definitivamente, en promedio una familia mixta de mujeres latinas y hombres franceses se forma anualmente. Los casos de divorcio y de separación no son despreciables, ya que al menos un matrimonio se disuelve siendo el hombre que permanece y que desposa una mujer europea. Nuestra muestra incluye un número similar de solteros y de miembros de una familia.

La población del estudio comporta en su mayoría individuos provenientes de grandes ciudades; los individuos que provienen de pequeñas ciudades son minoritarios. El nivel de estudios de las ultimas migraciones corresponde al tercer ciclo universitario, estudiantes varones en su mayoría. Las esposas tienen al menos un nivel de bachillerato, equivalente al BAC francés.

En esta muestra entre los datos culturales sobresalientes podemos mencionar un sentimiento intenso de la identidad nacional y cultural, un fuerte arraigo al país de origen, el papel importante de la familia en la organización de la vida individual y grupal, así como un profundo respeto de las tradiciones y las buenas costumbres. 
La discusión que planteamos resulta del cruce de dos ejes, uno el de las condiciones estructurales en las que se desarrollan las identidades y otro el de las similitudes y las influencias que existen entre estos grupos comunitarios y las acciones efectuadas en los últimos años.

\section{CUADRO TEÓRICO}

En este documento nos apoyamos en los trabajos teóricos de Castells (1999: 9-14) sobre la identidad. Según este autor, existen actualmente dos formas antagónicas que remodelan el mundo en el que vivimos: la globalización y el principio de identidad. Por otro lado, la evolución de las NTIC, crea un nuevo tipo de sociedad: la sociedad en redes.

El concepto de "identidad" aplicado a los actores sociales es un proceso de construcción de símbolos y de significados a partir de un atributo cultural o de un conjunto coherente de elementos culturales. En la sociedad en redes, la mayoría de los actores sociales organiza las significaciones en torno de una identidad dominante que impone su marco a los otros. Los procesos de construcción de la identidad reflejan las tensiones que se producen en la cultura del face-à-face, tensiones que se amplifican por el desarrollo de los mercados transnacionales del empleo y la amplitud de los flujos migratorios.

Castells hace una distinción entre una identidad que busca su legitimidad, que resiste o que construye un proyecto. Una identidad que resiste está formada por actores sociales que se encuentran en posición o condiciones desvalorizadas o señaladas por la lógica dominante, para resistir y sobrevivir, se confinan en "comunidades" basándose en principios extranjeros o contrarios a los que proclaman las instituciones sociales. Las "comunidades" elaboran formas de resistencia colectiva contra la opresión que de otra forma seria intolerable. Esto se hace basándose generalmente en identidades históricas, geográficas o biológicas, lo cual permite delimitar fácilmente las fronteras de la resistencia. El caso del grupo latino actual de Nancy se ha estructurado fundamentalmente en torno a una identificación geográfica. En los años 80 el grupo integraba también una componente histórica.

El proyecto de identidad surge cuando los actores sociales, basándose en el material cultural a su disposición, construyen una nueva identidad que define de otra forma su posición en la sociedad y que les permite la transformación de la estructura social.

El caso de la comunidad latinoamericana en Nancy pertenece a estas dos categorías, una resistencia de identificación y una identidad que se 
basa en estrategias para alcanzar un proyecto de identificación de un grupo minoritario "latino" que sea reconocido como tal.

Los individuos son los actores sociales colectivos en la construcción de la identidad, el cómo y el porqué dependen del contexto social. Los grupos minoritarios o grupos víctimas de una exclusión aspiran a una imagen positiva de la parte del grupo dominante. Los individuos pueden tener dos tipos de reacciones.

Un primer grupo de reacciones consiste en evitar el cuestionamiento, lo que puede hacerse de dos maneras:

- Definirse de una manera que les permita no estar considerados como el blanco del desprecio. Ciertos individuos de la muestra, declarándose Latinos, además de afirmar su diferencia, rechazan una nacionalidad controvertida.

- Otra asimilación consiste en abandonar sus referencias propias, adoptando completamente la cultura extranjera. Lo que puede observarse frecuentemente en la comunidad estudiantil en general.

- Se puede también ocultar el objeto de estigmatización, lo que se logra aislándose en el universo de origen lo que puede llevar a la separación. Los integristas musulmanes, por ejemplo. Formas tenues de estas estrategias consisten en ignorar o rechazar los juicios de desprecio. En este caso, encontramos las esposas o acompañantes de estudiantes.

- Se puede también retirarse del dúo dominante/dominado y de los valores que los rigen, lo que conlleva a la marginalización. Esto se puede efectuar en un sentido negativo si el individuo se adhiere a un grupo marginal, o en una dirección positiva cuando, por ejemplo, se une a un espacio "transcultural", donde la aculturación y las normas despreciativas serían sublimadas.

Un segundo grupo de reacciones consiste en afrontar activamente la desvalorización, lo cual se puede efectuar de dos maneras:

- Atacando al que estigmatiza o a sus juicios, intentando neutralizarlos por la argumentación o por otros medios. En este caso, podemos citar los foros de discusión, conferencias y exposiciones organizadas por algunas de las asociaciones que se han formado en esta ciudad.

- Se puede igualmente utilizar la identidad polémica por una afirmación de sí mismo, notablemente valorizando la marca estigmatizada por el adversario. El estereotipo del latino siempre listo 
para hacer la fiesta, se ha utilizado últimamente para la promoción de "soirées latinas".

Un tercer grupo de reacciones consiste en un compromiso que se establece entre la desvalorización crítica, es decir, la aceptación de ciertos juicios negativos y el rechazo de otros. Esta es una estrategia favorable a la integración, estrategia que consiste en la adopción de los rasgos del extranjero conservando un cierto numero de referencias de la cultura de origen.

Para los grupos minoritarios, los medios de comunicación masiva tienen una función complementaria a la de las instituciones encargadas de proteger y transmitir la memoria y la filiación. Al referimos a los medios de masa, no nos ceñimos únicamente a la radio, la televisión (Dayan, 1996) y la prensa, es necesario analizar los otros medios menos masivos para observar de cerca las prácticas, las instituciones y las asociaciones y así ver cómo estos grupos vinculan estos elementos (Dalhgreen, 1994).

En general, existen dos tipos de prácticas, las "tradicionales", como son las peregrinaciones, los rituales familiares y las fiestas religiosas. Sin embargo, la mayoría de las prácticas actuales se pueden considerar como "neotradicionales", ya que no son el producto de reminiscencias de otra época, sino que se trata de construcciones contemporáneas, de reapropiaciones conscientes de una cultura popular. Entre estas podemos considerar:

La producción y la difusión de boletines de información, de casetes de audio y de video. En las grandes ciudades la venta de productos "étnicos" es frecuente. En las pequeñas ciudades, el intercambio se efectúa entre los miembros de lo que podríamos llamar las "redes migratorias". Uno de los vínculos más fuertes en la comunidad latina es, sin duda, la música. De hecho es el tema preferido de las primeras conversaciones. El intercambio o el préstamo de $\mathrm{CD}$ es una de las principales actividades.

La constitución de una comunidad religiosa y de las asociaciones culturales reagrupa individuos de orígenes parecidos, que son atraídos por la naturaleza del culto o el estilo de interacción.

El trabajo de campo nos ha permitido identificar en el universo religioso varias referencias que conciernen tanto a la construcción de una imagen del individuo, a la elaboración de una representación de la comunidad y a la estructuración de sus relaciones con la sociedad huésped. Las personas que hemos interrogado tuvieron la posibilidad o la necesidad en algunos casos de convocar a las estructuras de la iglesia 
para organizar una acción colectiva. Es a través de la iglesia que descubren la posibilidad de participar a la vez como individuos y como comunidad. Ya que la forma religiosa para la reconstrucción de la identidad no sigue los mismos esquemas, la delimitación de la experiencia individual y colectiva es de una gran importancia.

La creación de redes entre los diferentes grupos minoritarios, ya sea para la difusión de directivas de las organizaciones religiosas o políticas según objetivos precisos. El uso de Internet ha modificado ampliamente la comunicación entre los diferentes miembros de la comunidad, como es el caso de la misa mensual. Estas reuniones se organizan de manera que en un primer tiempo se asista a la misa en español y a continuación una reunión en la que se comparten los diferentes platillos de los asistentes al servicio.

El intercambio de cartas, fotografías, llamadas telefónicas o mensajes electrónicos. La utilización de la nuevas tecnologías en el intercambio de informaciones de importancia para los diferentes miembros de la comunidad, que van del simple saludo, las direcciones importantes administrativas, consejos culinarios, etc.

Los latinoamericanos de Nancy han comprendido la importancia que tiene la construcción de un pasado, mismo si éste se basa en referencias míticas, a través de una reinterpretación de la memoria colectiva. Este grupo re-estructura su discurso utilizando las referencias simbólicas latinoamericanas otorgando así un lugar privilegiado a la diferencia cultural de los diferentes miembros de esta comunidad. De su evolución y de su relación con los procesos de formación de la identidad cultural obtendría una visibilidad positiva de esta población minoritaria y de sus costumbres comunitarias, que podrían contribuir al desarrollo de una nueva visión de la inmigración latinoamericana.

El espacio otorgado a los inmigrantes se ha considerado desde finales del siglo XIX como un problema que éstos deben enfrentar, ya sea que se trate de lugares de recepción provisorios, de alojamientos individuales, hotel, pensiones o de ciudades obreras, dedicadas a recibir familias completas. Para algunos inmigrantes estos lugares pueden convertirse en auténticos cementerios de la memoria colectiva, fenómeno que parece constituir un terreno favorable al desarrollo tan temido de "comunidades" ilícitas. Es importante que el paso de la comunidad invisible no se dirija hacia los terrenos sombríos del "comunitarismo".

Como resultado de nuestro trabajo estadístico en el censo de población -INSEE-, hemos podido constatar que la presión de los movimientos del capital y de la libre circulación de bienes en un mercado "global" pone en competencia a los trabajadores a una escala internacional 
e impone una tendencia a la generalización del trabajo precario aun en los países ricos. La aceleración y la generalización de las migraciones transnacionales, en sus formas reglamentarias, conciernen un pequeño número de profesionales altamente cualificados que evolucionan esencialmente en el cuadro de un mercado globalmente integrado, propio de ciertos sectores económicos.

\section{CONCLUSIÓN}

La integración en la sociedad huésped es el principal objetivo a alcanzar de ciertas poblaciones o grupos minoritarios. Se revela además como punto de partida de nuevas construcciones y búsquedas de identidad. El discurso sobre la identidad está lejos de ser una unidad coherente. Los medios que permiten la supervivencia de ciertos grupos tienden en ocasiones a proporcionar versiones antagónicas de esa identidad. Ciertas versiones pueden ser catastróficas, otras, lo contrario, es decir, hay toda una gama de retóricas de identidad y numerosas maneras de transmitir los conocimientos necesarios para la construcción de una comunidad.

La globalización es una manera bivalente de considerar desde al individuo hasta la relación entre las naciones. Esta nueva perspectiva implica la reinvención de la buena graduación entre lo local y lo mundial, esto en todos los aspectos de la vida social: en la familia, la escuela, el trabajo, la iglesia, como en la vida política. En la actualidad, el hacerse "visibles" es una prioridad para los grupos minoritarios, ser reconocidos como tales, construirse un rostro, un nombre, una historia. Para que esta tarea se realice en las mejores condiciones es necesaria la utilización de las NTIC, que son paradójicamente un producto de la globalización.

\section{BIBLIOGRAFÍA}

CASTELLS, M. Le pouvoir de l'identité, Paris, Fayard, 1999.

DAHLGREN, P. L'espace public et les médias: une nouvelle ère?, Paris, Hermès, 1994.

DAYAN, D. et KATZ, E. La télévision Cérémonielle, Paris, PUF, 1996.

DUBAR, C. La crise des identités, Paris, PUF, 2000.

NEVEU, E. Sociologie des mouvements sociaux, Paris, La Découverte, 2000.

NOIRIEL, G. L'Atlas de l'immigration en France, Paris, Autrement, 2002.

RUANO-BORBALAN, J.C. L'identité, Paris, Sciences Humaines, 1998. 